\title{
Collagen-Based Films Containing Liposome-Loaded Usnic Acid as Dressing for Dermal Burn Healing
}

\author{
Paula S. Nunes, ${ }^{1}$ Ricardo L. C. Albuquerque-Júnior, ${ }^{2}$ Danielle R. R. Cavalcante, ${ }^{2}$ \\ Marx D. M. Dantas, ${ }^{2}$ Juliana C. Cardoso, ${ }^{2}$ Marília S. Bezerra, ${ }^{1}$ Jamille C. C. Souza, ${ }^{1}$ \\ Mairim Russo Serafini, ${ }^{1}$ Lucindo J. Quitans-Jr, ${ }^{1}$ Leonardo R. Bonjardim, ${ }^{1}$ \\ and Adriano A. S. Araújo ${ }^{1}$ \\ ${ }^{1}$ Departamento de Fisiologia, Universidade Federal de Sergipe, Avenida Marechal Rondon, s/n, Cidade Universitária, \\ CEP 49100-000, São Cristóvão, SE, Brazil \\ ${ }^{2}$ Programa de Pós-Graduação em Saúde e Ambiente-Universidade Tiradentes, SE, Avenida Murilo Dantas, 300, \\ CEP 49032-490, SE, Brazil
}

Correspondence should be addressed to Adriano A. S. Araújo, left.ufs@hotmail.com

Received 8 June 2010; Revised 30 August 2010; Accepted 22 October 2010

Academic Editor: Monica Fedele

Copyright (c) 2011 Paula S. Nunes et al. This is an open access article distributed under the Creative Commons Attribution License, which permits unrestricted use, distribution, and reproduction in any medium, provided the original work is properly cited.

\begin{abstract}
The aim of this study was assess the effect of collagen-based films containing usnic acid as a wound dressing for dermal burn healing. Second-degree burn wounds were performed in forty-five Wistar rats, assigned into nine groups: COL-animals treated with collagen-based films; PHO_-animals treated with collagen films containing empty liposomes; UAL_animals treated with collagen-based films containing usnic acid incorporated into liposomes. After 7, 14, and 21 days the animals were euthanized. On 7th day there was a moderate infiltration of neutrophils, in UAL, distributed throughout the burn wounds, whereas in COL and $\mathrm{PHO}$, the severity of the reaction was slighter and still limited to the margins of the burn wounds. On the 14th day, the inflammatory reaction was less intense in UAL, with remarkable plasma cells infiltration. On the 21st day, there was reduction of the inflammation, which was predominantly composed of plasma cells in all groups, particularly in UAL. The use of the usnic acid provided more rapid substitution of type-III for type-I collagen on the 14th day, and improved the collagenization density on the 21st day. It was concluded that the use of reconstituted bovine type-I collagen-based films containing usnic acid improved burn healing process in rats.
\end{abstract}

\section{Introduction}

Disruption of the skin generally leads to an increased fluid loss, infection, hypothermia, scarring, compromised immunity, and change in body image; furthermore, large skin damage can cause mortality [1]. The concern on the high cost of treatment, resistance to antibiotics, inability to restore initial appearance of the skin, and the high rates of septicemia related to severe burn wounds has increased in the last decades [2] so that various formulations such as ointments and wound dressings have been developed for the treatment of these lesions [3].

Natural polymers have been increasingly studied for applications in health care due to their biocompatibility, biodegradability, and nontoxity $[4,5]$. Collagen-based film is a potentially useful biomaterial, since it is the major constituent of the connective tissue and permit controlled drug release within target tissues [6]. The main applications of collagen as drug-delivery systems are collagen shields in ophthalmology, sponges for burns/wounds, gel formulation in combination with liposomes for sustained drug delivery, and controlling material for transdermal delivery $[7,8]$.

Usnic acid (UA), a dibenzofuran originally isolated from lichens [9], has been shown to work as a growth regulator in higher plants $[10,11]$. In humans, it can act as an antiinflammatory [12], antimitotic [13], antineoplasic [14, 15], antibacterial [16], and antimycotic [17] agent. However, the potential benefits of UA therapeutic application are limited by its unfavorable physicochemical properties, particularly its very poor water solubility. Therefore, its use in a safe and 
<smiles></smiles>

FIgURE 1: Molecular structure of usnic acid.

efficient manner requires a suitable solubilizer agent and/or carrier system for improving the therapeutic index of this drug $[18,19]$.

A wide variety of drugs has been incorporated into or associated with liposomes and nanocapsules, as long as such materials represent excellent drug carrier systems [2022]. Liposomes are vesicles composed of a bilayer of lipid molecules enclosing an aqueous volume. Recent applications have concentrated on their use as drug-delivery vehicles due to the ability of incorporating water-soluble materials in their aqueous volume or oil-soluble materials in the lipid bilayer [23]. It has been reported that the encapsulation of UA has shown to be a suitable strategy to reduce the hepatotoxicity [15] and to overcome the low water solubility [18] of this molecule, providing safety and efficiency to its use in health care.

\section{Experimental}

2.1. Materials. Usnic acid, 2,6-diacetyl-7,9-dihydroxy-8, 9bdimetyl-1,3(2H,9bH)-dibenzeno-furandione (Figure 1) was isolated from Cladonia substellata Vainio collected in March, 2006 , in the Itabaiana county $\left(180-670 \mathrm{~m} ; 10^{\circ} 41^{\prime 2} 22^{\prime \prime ~ S}\right.$; $\left.37^{\circ} 24^{\prime \prime} 10^{\prime \prime} \mathrm{W}\right)$, Sergipe-SE, Brazil. Lichen sample was identified by M.P. Marcelli (Botanical Institute of São Paulo-SP, Brazil), where a voucher specimen was deposited (Deposit no. SP393249). All chemicals were of reagent grade. The collagen was prepared according to the method proposed by Cardoso (2005) [24].

2.2. Extraction and Purification of Usnic Acid. Air-dried lichen $(300 \mathrm{~g})$ was extracted with diethyl ether in a Soxhlet apparatus and the precipitate formed on cooling collected, recrystallized from ethanol, yielding $330 \mathrm{mg}$ usnic acid [25].

2.3. Films Preparation. Collagen-based films (CL) were prepared through casting method using collagen dispersion (2\%) in $0.5 \mathrm{M}$ acetic acid with $20 \%$ of plasticizer (propyleneglycol-Isofar Lot. 070967) in relation to the polymer dry weight. This dispersion was casted onto a clean rimmed perspex plate and allowed to dry at room temperature in order to obtain the films.

UA-loaded liposomes were prepared by conventional rotary evaporation method. Briefly, phosphatidylcholine (Lipoid GMBH 75\% Lot 776095-1) was dissolved in chloroform according to the ratio phosphatidilcoline/usnic acid of $18: 1 \mathrm{w} / \mathrm{w}$. The mixture was dried to a thin lipid film using a rotary evaporator. This film was kept in desiccator for at least $24 \mathrm{~h}$ until the organic solvent was totally eliminated. Then, the lipid film was hydrated and dispersed in water, under vigorous magnetic agitation, promoting the formation of the multilamellar vesicles (MLV). Small unilamellar vesicles (SUV) were prepared by probe sonication of the MLV dispersion. After this procedure, the usnic acid-loaded liposomes were mixed with collagen dispersion $(2 \%$ in $0.5 \mathrm{M}$ acetic acid with collagen dispersion (2\%): $20 \%$ of propyleneglycol $\mathrm{w}: \mathrm{w})$ in the ratio of $1: 4(\mathrm{v} / \mathrm{v})$. After solvent evaporation, the films were cut off in square shape $(2 \times 2 \mathrm{~cm})$ and sterilized using UV rays (20 min) in order to obtain the usnic acid/collagen-based films (UAL). The characterization of usnic acid/collagen-based films was reported in previous research [26].

2.4. Animals. The animals used in this study were adult male Rattus norvegicus albinus, Wistar lineage, weighing 250$300 \mathrm{~g}$. The rats were housed in clear plastic cages with solid floors and loose hardwood chip bedding, in a temperature and humidity-controlled environment, and supplied with food and water ad libitum. Experimental protocols and procedures were approved by the Federal University of Sergipe Animal Care and Use Committee (CEPA/UFS no. 08/09).

2.5. Burning Procedures and Groups. Forty-five male Wistar rats $(250 \pm 50 \mathrm{~g})$, supplied with food and water ad libitum in a temperature and humidity-controlled environment, were anesthetized with intraperitoneal ketamine-xylazine $(100 \mathrm{mg} / \mathrm{kg}-5 \mathrm{mg} / \mathrm{kg})$. The burn wounds were performed in the back of the animals by the contact of a heated $1 \mathrm{~cm}^{2}$ standard-sized square-shaped copper plate with the skin for $20 \mathrm{~s}$. Animals were handled in accordance to the principles of aseptic chain in order to avoid bacterial contamination. Subsequently, rats were randomly assigned into three groups of fifteen animals each: COL_animals treated with collagenbased films; $\mathrm{PHO}$ - animals treated with collagen films containing empty liposomes; UAL - animals treated with collagen-based films containing usnic acid incorporated into liposomes. After 7, 14, and 21 days, five animals of each group were euthanized by intramuscular administration of $0.8 \mathrm{~mL} / \mathrm{Kg}$ zoletil, $0.43 \mathrm{~mL} / \mathrm{Kg}$ Tiopental and $5 \mathrm{~mL} / \mathrm{K}$ potassium chloride $\mathrm{g}$ (Ariston 19, 1\%, 2,559 $\mathrm{mEq} / \mathrm{mL}$ ), and the area corresponding to the wound region in the back of the animals was surgically removed and formalinfixed for further histological examination.

2.6. Histological Procedures. The surgical specimens were formalin-fixed and paraffin-embedded according to the routine laboratorial techniques. Subsequently, serial $5 \mu \mathrm{m}$ thick sections were obtained and stained in hematoxylineosin and picrosirius.

2.6.1. Assessment of the Inflammatory Profile (IP) and Epithelization Rates (ER). Histological sections stained in hematoxylin-eosin were used to the descriptive analysis of the inflammatory profile (IP) and epithelization rates (ER). 
The intensity of the inflammatory response was assessed as follows: + (inflammatory cells representing less than $10 \%$ of the cell population observed within the wound area), ++ (inflammatory cells representing between 10 and $50 \%$ of the cell population observed within the wound area), and +++ (inflammatory cells representing more than $50 \%$ of the cell population observed within the wound area). Moreover, the profile inflammatory (IP) was classified as acute (predominance of polymorphonuclear cells) and chronic (predominance of mononuclear cells) and graded as slighter/absent, moderate, or severe. In order to assess the epithelization rates (ER), photomicrographs of the wounds were taken from all the samples $(40 \mathrm{x})$ and processed in a software (ImageLab, Sof- tium, São Paulo, SP, Brasil). The total wound surface extent (TWE) was assessed, as well as the extent of the epidermal migration from the normal wound margin to the point where the migrating epithelium stopped processing (ME). ER (\%) was determined as follows:

$$
\mathrm{ER}(\%)=\frac{(\mathrm{ME} \times 100)}{\mathrm{TWE}} .
$$

2.6.2. Assessement of the Collagen Deposition. Histological sections stained in picrosirius and analyzed under polarized light were used to the descriptive analysis of the collagen deposition. Collagen fibers were analyzed according to their birefringence pattern (greenish/yellow-greenish or orange, orange-reddish), morphological appearance (wavy or stretched, thin or thick, short or long), and disposition (reticularly arranged or interlaced).

The quantitative analysis of the area occupied by collagen fibers in the healing area was determined by optical density in the image analysis system in different randomly selected fields. The system used consists of a CCD Sony DXC-101 camera, applied to an Olympus CX31 microscope, from which the images were sent to a monitor (Trinitron Sony). By means of a digitizing system (Olympus C-7070 WIDEZOOM) the images were inserted into a computer (Pentium $133 \mathrm{MHz}$ ), and processed by a software (ImageTool). A total of ten fields per case were analyzed at a magnification of 100x. The thresholds for collagen fibers were established for each slide, after enhancing the contrast up to a point at which the fibers were easily identified as birrefringent (collagen) bands. The area occupied by the fibers was determined by digital densitometric recognition, by adjusting the threshold level of measurement up to the different color densities of the collagen fibers. The area occupied by the fibers was divided by the total area of the field. The results were expressed in percentage of the skin area fraction occupied by the collagen fibers.

\subsection{Assessment of the Mean of Myofibroblasts for Histological} Field $(M F)$. Myofibroblasts were detected by using a monoclonal antibody against the $\alpha$-smooth muscle actin antigen (clone 1A4; 1:200, $12 \mathrm{~h}$, Dako, Glostrup, Denmark). After washing in PBS, slides were incubated with biotin-labeled antimouse secondary antibodies (Vector Laboratories Inc., Burlingame, CA), then washed in PBS, and incubated with
TABLE 1: Assessment of the intensity of the inflammatory infiltrate in the COL (collagen group), PHO (collagen/liposome group), and UAL (collagen/liposome/usnic acid group), in 7, 14, and 14 days after burning procedures.

\begin{tabular}{ccccc}
\hline \multirow{2}{*}{ Time } & \multirow{2}{*}{ Animals } & \multicolumn{3}{c}{ Inflammatory reaction intensity } \\
& & COL & LIP & UAL \\
\hline \multirow{4}{*}{ 7th } & R1 & + & ++ & +++ \\
& R2 & ++ & + & +++ \\
& R3 & ++ & + & ++ \\
& R4 & + & ++ & +++ \\
& R5 & + & + & +++ \\
\hline \multirow{6}{*}{14 th } & R1 & ++ & +++ & +++ \\
& R2 & +++ & +++ & ++ \\
& R3 & ++ & +++ & ++ \\
& R4 & +++ & +++ & ++ \\
& R5 & +++ & ++ & ++ \\
& R1 & ++ & ++ & + \\
21 st & R2 & ++ & ++ & + \\
& R3 & + & ++ & + \\
& R4 & + & + & ++ \\
& R5 & + & + & + \\
\hline
\end{tabular}

$+=$ mild inflammatory infiltrate, representing less than $10 \% ;++=$ moderate inflammatory infiltrate, representing between 10 and $50 \%$; +++ = intense inflammatory infiltrate, representing more than $50 \%$.

peroxidase-labeled streptavidin (DAKO). The reaction products were visualized by immersing the slides in freshly prepared diaminobenzidine (Dojindo, Kumamoto, Japan). Ten histological sections $\left(\times 40,10\right.$ ocular, $0.739 \mathrm{~mm}^{2}$ per field $)$ were randomly selected and the mean of immunostained cells was assessed with an image analysis system Imagelab (Sof- tium, São Paulo, SP, Brasil) as previously described by Ribeiro et al. (2009) [27]. Only spindle-shaped and round cells scattered in the connective tissue we regarded as myofibroblasts whereas positive cells observed right around the blood vessels were considered as pericytes and, therefore, were excluded of the study [27].

2.8. Statistical Analysis. Statistical significant difference in the severity of the inflammatory reaction was assessed by chisquared test whereas the significances of the differences in the ER, MF, and collagenization rates were verified by analysis of variance (one-way ANOVA) and Tukey test. Each time point was analyzed separately, and two-tailed $\alpha$-level of $P<.05$ was significant.

\section{Results and Discussion}

As showed in Table 1, on the seventh day, the intensity of the inflammatory response was severe in UAL although in $\mathrm{COL}$ and $\mathrm{PHO}$, it ranged from mild to moderate. Besides, there was an expressive infiltration of neutrophils, in UAL (Figure 2(Ic)), distributed throughout the burn wounds whereas in COL and PHO it was still limited to the margins and bottom of the burn wounds (Figure 2(Ia) and (Ib)). Moreover, a poorly developed granulation tissue was 

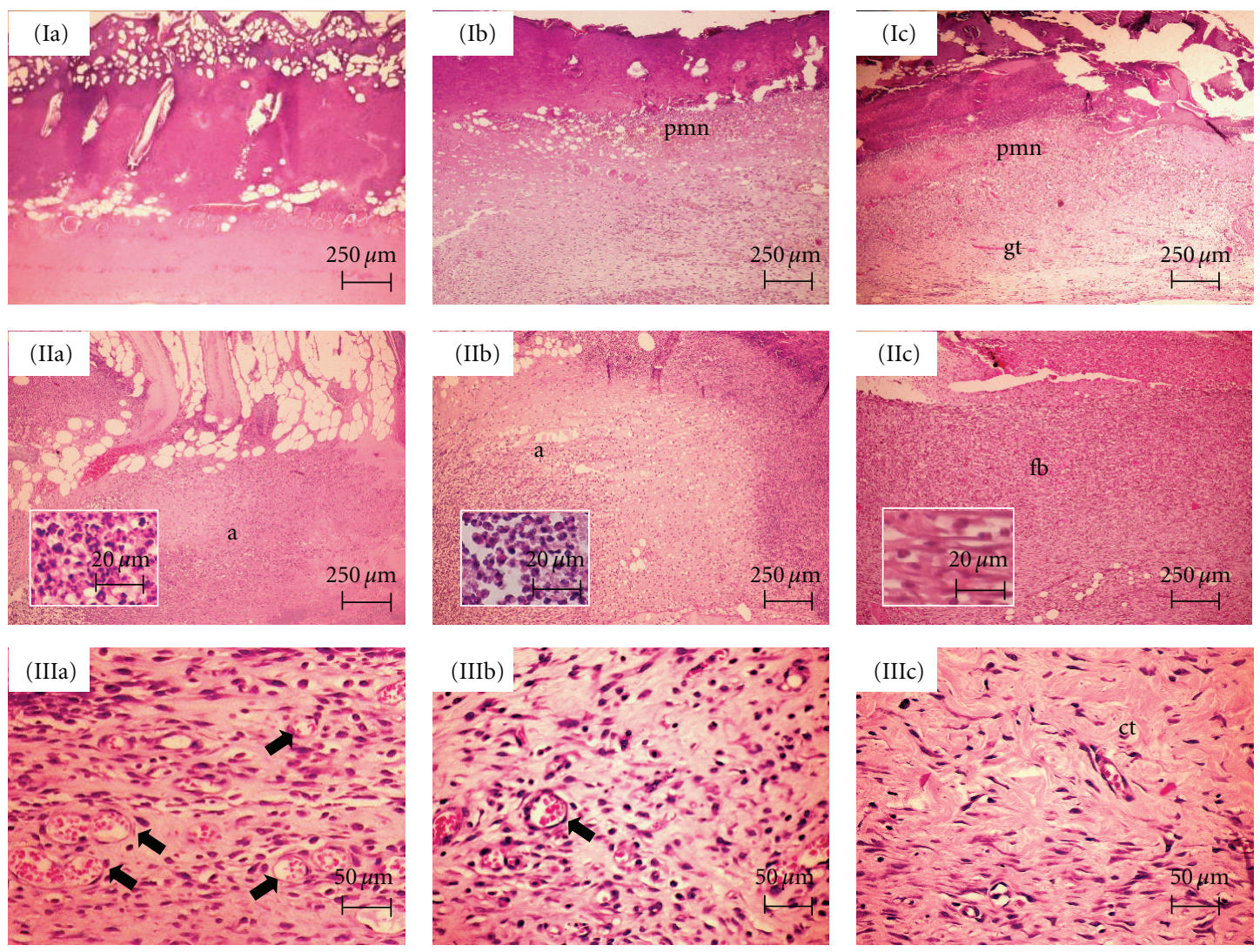

Figure 2: Histological sections stained in HE. Seven days: (Ia) Lack of inflammatory response in the center of the burned area in COL. (Ib) Inflammatory infiltrate rich in polymorphonuclear neutrophils (pmn) in PHO. (Ic) Expressive content of polymorphonuclear neutrophils (pmn) in the top of the wound, and early granulation tissue (gt) formation in the bottom, in UAL. Fourteen days: (IIa and IIb) Intense acute inflammatory reaction (a) scattered within the burned area in COL and PHO, respectively. Neutrophils seen in detail. (IIc) Moderate infiltrate of neutrophils and lymphocytes in association to expressive fibroblastic proliferation (fb) in UAL. Fibroblasts seen in detail. Twentyone days: (IIIa and IIIb) Vascular component (arrows), and chronic inflammatory infiltrate, still evident in COL and PHO, respectively. (IIIc) Scanty inflammatory cells are seen within the cicatricial tissue (ct) in UAL.

observed in all groups, but the vascular content was also more evident in UAL. These findings were expected, since soon after injury, as a result of vascular and biochemical changes, a substantial amount of neutrophils migrate into the wound to prevent the invasion and proliferation of microorganisms; subsequently, these polymorphonuclear cells are gradually replaced by mononuclear cells as the wound healing continues, in a bottom-top process [28].

After 14 days, the severity of the inflammation (Table 1) ranged from moderate to intense, with chronic profile in the bottom and acute in the top of the burn wounds, in COL and PHO groups (Figure 2(IIa) and (IIb)) whereas in UAL it was predominantly moderate (Figure 2(IIc)). The reason for the maintenance of intense inflammation in the group treated with collagen films, without usnic acid, lies on the fact that, although collagen presents plenty of biomodulatory effects, these molecules do not exhibit anti-inflammatory activity [29]. However, COL and PHO showed lymphocyte-rich infiltrate whereas an expressive content of plasma cells was observed in UAL in addition to the lymphocytic infiltrate. Besides, the exuberant granulation tissue observed in UAL, in opposition to the less fibrovascular lymphocyte-rich tissue seen in COL and PHO, suggests that the use of collagenbased films containing usnic acid apparently favored the installation of the earlier events involved in wound healing process.

Finally, 21 days after the burn procedures, the severity of the inflammatory reaction was evidently reduced in UAL in comparison with the other groups (Table 1). These findings might be related to the usnic acid biological properties, which may be involved in the inhibition of prostaglandin synthesis, similarly to nonsteroidal anti-inflammatory drugs [30]. The few inflammatory cells observed in UAL (Figure 2(IIIc)) were composed almost exclusively by plasma cells, in opposition to the still expressive presence of lymphocytes in $\mathrm{COL}$ and $\mathrm{PHO}$ (Figure 2(IIIa) and (IIIb)). Therefore, it is suggested that the use of UAL might provide acceleration of the latter phases of the immunological response, such as B cells activation and differentiation into plasma cells. On the other hand, the maintenance of lymphocyte-rich infiltrate in COL and $\mathrm{PHO}$ suggests that the biological events that characterize the local immunological response are taking place more slowly in these groups. Whereas residual granulation tissue composed 
by some few clusters of dilated and congested capillary blood vessels tissue was still observed in the surface of the burn wounds, in addition to an extremely cellular connective tissue, in COL and PHO, it could not be evidenced in UAL, which showed connective tissue represented by dense collagen-rich cicatricial scar. This is suggesting that the healing process was substantially advanced in the groups treated with UA. The improvement in the skin wound healing induced by usnic acid has been previously reported, although this effect had not been mediated by fibroblasts proliferation [31].

Therefore, the epithelization is considered a relevant step of wound healing, once keratinocytes are supposed to be source of cytokines involved in remodeling the collagen fibers deposited at the final stages cicatricial repair. The ER was significantly higher in UAL than in COL $(P=.040)$ and PHO $(P=.044)$ in 7 days, but there was no significant difference among the groups either in $14(P=.153)$ or in 21 days $(P=.09)$ (Figure 3$)$. These findings might be related to the fact that the molecules of usnic acid were probably released into the insulted area during the first days of the healing process, as long as the collagen-based film is resorped. Thus, considering that usnic acid has been previously proved to work as mitogen factor for keratinocytes in in vitro assays [32], the lichenic metabolite would act directly on epithelial cells in the edge of the wounds, providing cell proliferation and migration to form the new superficial lining earlier than in the other groups.

The method of picrosiriuspolarization has contributed substantially for the identification and comprehension of the collagen and its function. This method is based on the presence of alkaline aminoacids in the collagen molecules that strongly react with the acid stain (Sirius red). This process increases the birefringence of the normal aggregated collagen molecules. Besides, differentiation between the types of collagen is also possible, since the type I is intensely birefringent (yellow-orangish and reddish) and composed of long thick fibers whereas type III is less birefringent (greenish) and constituted by short, thin delicate fibers [33].

In this study, only scanty deposition of thin delicate reticularly arranged fibrils exhibiting greenish and yellowgreenish birefringence (type-III collagen) was observed in all groups after seven days. In UAL (Figure 4(Ic)), the fibers appeared thicker and longer than in $\mathrm{COL}$ and $\mathrm{PHO}$ (Figure 4(Ia) and (Ib)), particularly in the margins of the burn wounds. Inconspicuous deposition of collagen fibrils was expected, since the collagen synthesis begins around the fifth day, in order to provide spatial orientation of angioblasts during the very early stages of wound healing [34].

At 14 days, there was a remarkable improvement of the colagenization in UAL, since deposition of gross wavy parallel-arranged bundles of birefringent yellow-orangish collagen fibers (type-I collagen) was observed (Figure 4(IIc)). Oppositely, COL and PHO exhibited deposition of long but still delicate collagen fibers, composed predominantly by type III collagen (Figure 4(IIa) and (IIb)). The high content of collagen fibers, in addition to the dense arrangement and wavy appearance of the bundles, suggests that this lichenic constituent might play an important role in the fibroplasias

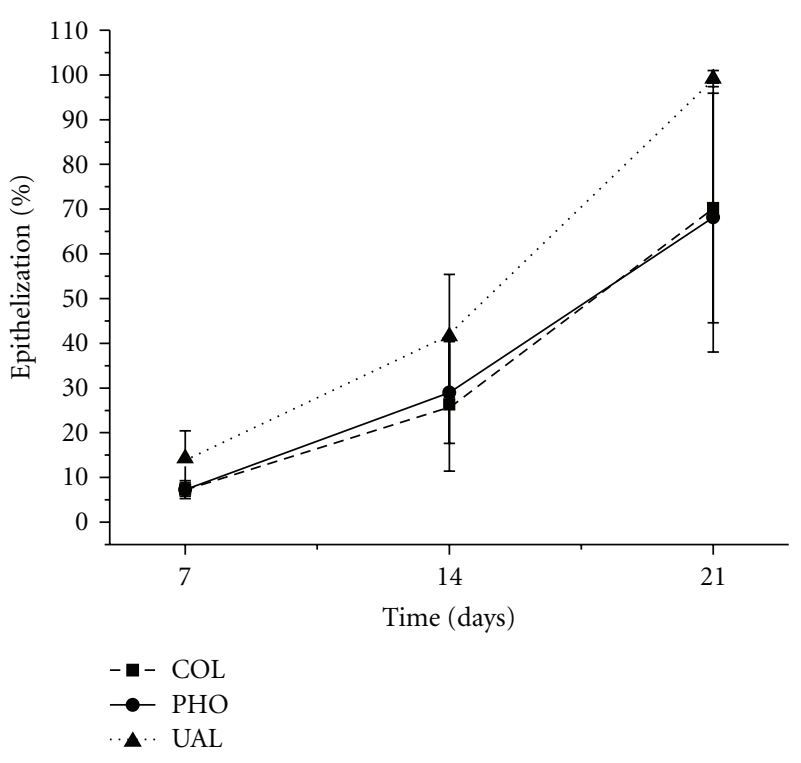

Figure 3: Epithelization of the burn wound surface.

dynamic. This hypothesis is also supported by the thicker appearance of the fibers in UAL even in the seventh day samples.

At 21 days, it evidenced intense deposition of gross thick parallel-arranged collagen bundles, less densely deposited in the top of the scars, and apparent complete resorption of type III fibers, in COL and PHO (Figure 4(IIIa) and (IIIb)). Nevertheless, UAL showed a mix of wavy and highly interlaced type I and type III collagen fibers, whose arrangement resembled the normal dermis (Figure 4(IIIc)). The replacement of a substantial part of the content of type III collagen for type I molecules during the healing process is an absolutely expected phenomenon $[35,36]$. However, the excessive production of type I collagen, as observed in COL and PHO, might easily lead to the formation of undesirable hypertrophic scars and keloids $[37,38]$. On the other hand, the moderate content of less thick collagen fibers in UAL appears to provide low probability of keloid development, a quite desirable property in prohealing materials. Besides, the pattern of arrangement and balance in the content of both type I and type III collagen fibers as seen in UAL seems to suggest that the remodeling phase of the scar, represented by degradation of the gross connective matrix formed and gradual and progressive deposition of a new depurated matrix rich in both collagen molecules, is highly advanced in comparison to the other groups, which would justify the clear resemblance with the normal histological appearance of the dermal collagen. It must also be stressed that despite the biological effects of usnic acid on the fibroplasia dynamics, this seems to be probably related to a possible increase in the fibroblast metabolism, as long as both synthesis and degradation of the collagen molecules were apparently stimulated in this study, further investigations are required in order to fully clarify the precise mechanism of the healing modulation pathways provided by this lichenic constituent. 

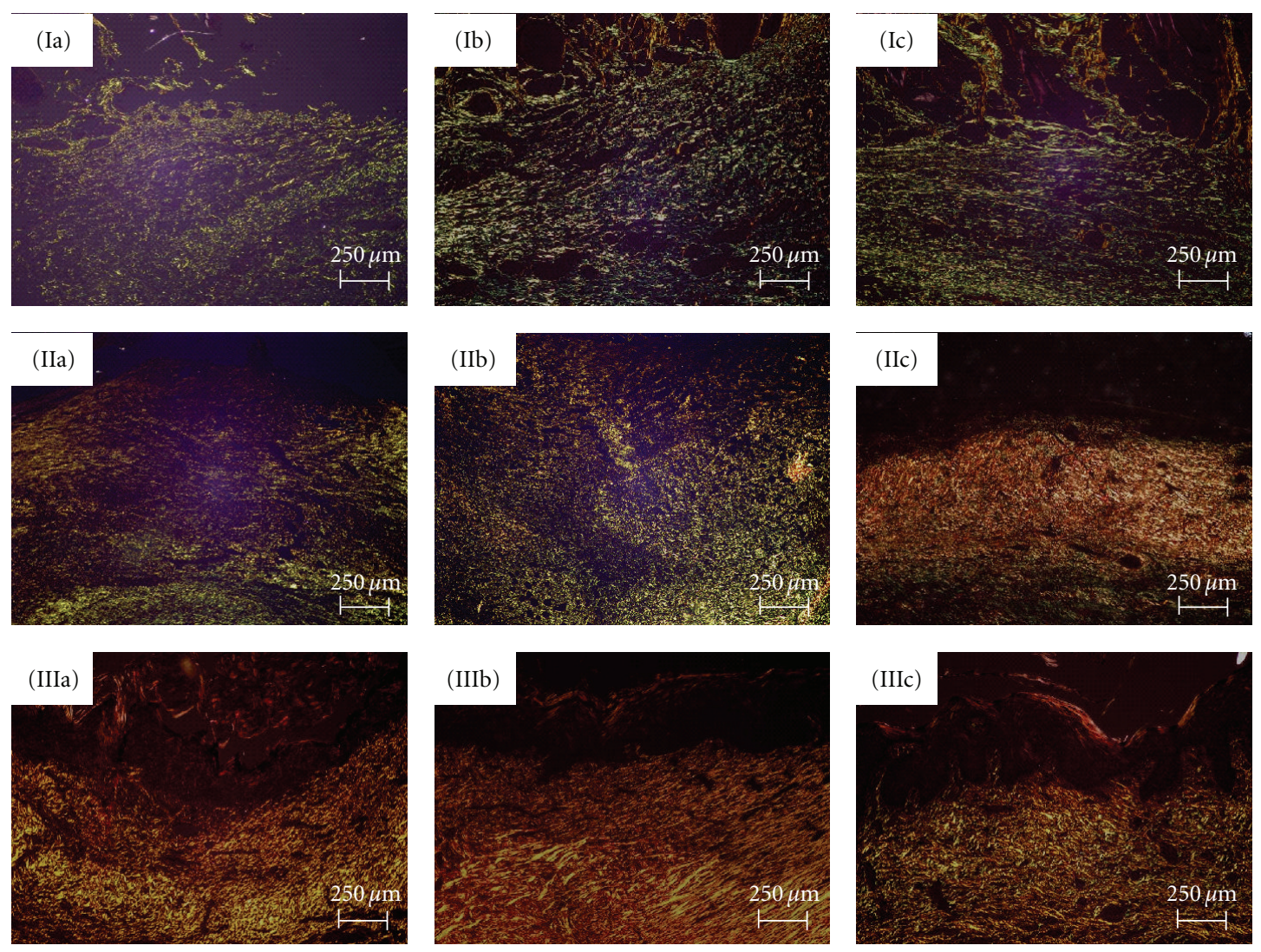

FIGURE 4: Histological sections stained in Sirius red, analyzed under polarized light. Seven days: thin delicate reticularlyarranged type-III collagen fibrils seen in COL (Ia), PHO (Ib), and UAL (Ic). Fourteen days: predominance of type-III collagen fibrils is maintained in COL (IIa), and PHO (IIb), whereas in UAL (IIc) there is predominance of type-I collagen fibers. Twenty-one days: intense deposition of type I collagen fibers seen in COL (IIIa) and PHO (IIIb) whereas in UAL, a mix of wavy and highly interlaced type I and type III collagen fibers is seen.

As shown in Figure 5, the quantitative analysis of the collagen deposition revealed that in seven days the content of collagen fibers in COL was significantly less expressive than in PHO $(P=.02)$ and UAL $(P=.02)$, but there was no difference between these last two groups $(P=.20)$. No difference among the groups was observed in 14 days $(P=.20)$. In 21 days, collagenization was more expressive in PHO than in COL $(P=.00)$, but there was no difference either between PHO and UAL $(P=.25)$, or COL and UAL $(P=.16)$. Besides, the content of collagen in unwounded rats skins (URS) was similar to PHO $(P=.44)$ and UAL $(P=.16)$, but higher than in COL $(P=.006)$.

Despite strong evidence that certain phospholipids and fatty acids are involved in the regulation of proinflammatory cytokines release during wound healing have been previously reported [24], the current study provides evidences that the liposome phospholipids might also influence the collagen synthesis. However, the profitableness of these findings is questionable, since the over production of collagen may be result in hypertrophic scars.

On the other hand, the presence of usnic acid within the liposomes avoided the over deposition of collagen fibers. Therefore, this lichenic metabolite appeared to minimize possible deleterious effects of the liposomes on the collagenization, particularly if considered that the content of collagen deposited in this group was statistically equivalent to the one observed in unwounded dermis. In addition, taken together, the data obtained after descriptive and quantitative analysis of the collagen content in UAL seem to be quite complementary, as long as point at a possible role played by this usnic acid on the fibroblasts metabolism.

Regarding the MF (Figures 6 and 7), no significant difference was verified among the groups in 7 days $(P=.30)$. In 14 days, the content of myofibroblasts was significantly higher in PHO and UAL than in COL $(P=.005$ and 0.000 resp.), but no difference was evidenced between $\mathrm{PHO}$ and UAL $(P=.42)$. However, in 21 days, the myofibroblasts content was significantly reduced in UAL compared to COL $(P=.000)$ and $\mathrm{PHO}(P=.002)$.

Myofibroblasts are a cell type involved in wound contraction. These cell subsets present a contractile phenotype characterized by a cytoskeleton rich in actin microfilaments, and they can be identified by immunohistochemistry due to their extensive positivity for $\alpha$-SMA (alpha sooth muscle actin) $[27,39]$. Therefore, myofibroblastic differentiation is supposed to be a crucial event leading to a suitable healing 

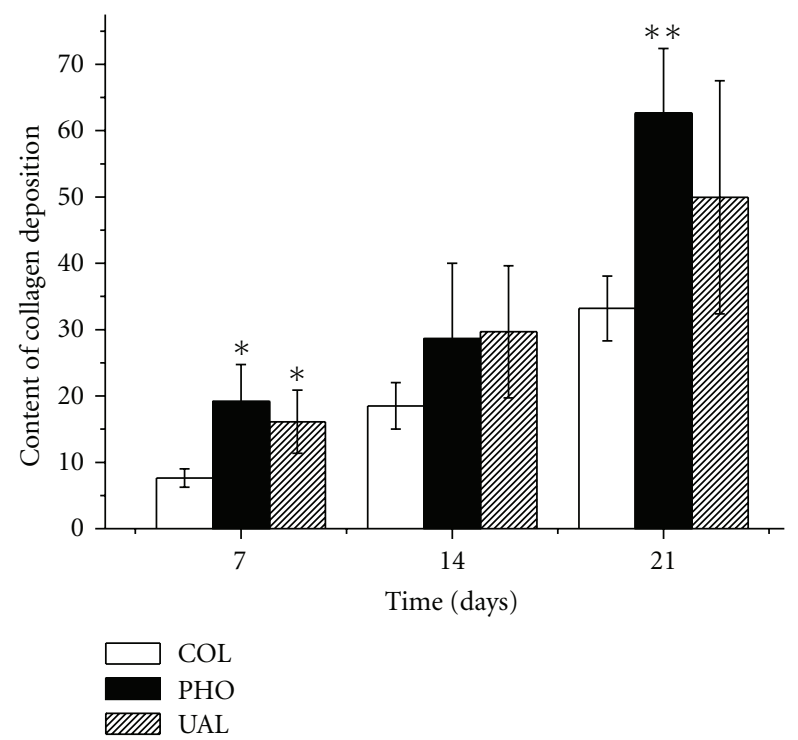

Figure 5: Quantitative analysis of the collagen content in the studied groups seven, 14 and 21 days after the burn procedures (COL—collagen-based dressing films; $\mathrm{PHO}$ — phospholipidscontaining collagen-based dressing films; UAL-liposome-loaded usnic acid-containing dressing films). ${ }^{*}$ Different from COL $P=$ $.02{ }^{* *}$ Different from COL $P=.000$.

of larger wounds, which have more extensive loss of cells and tissue [27]. In this study, the application of collagen-based films containing liposomal-loaded usnic acid might have provided fibroblastic transformation into myofibroblasts at the early stages of the burn healing process. Notwithstanding, in 21 days, the number of myofibroblasts decreased, most likely due to apoptosis, and scar tissue were formed. On the other hand, in COL and PHO, the healing process appeared to be considerably slower, so that the process of myofibroblastic apoptosis apparently had not yet taken place. However, further studies are necessary to clarify if this cell phenotype transformation is a direct effect of the usnic acid itself, or a result of the release of differentiating factors by other cells involved in the healing process.

It must be emphasized that several of the $\alpha$-SMA positive cells observed in this study were disposed surrounding the newly formed blood vessels, and some of them appeared to be detaching from the capillaries and venules, and they were identified as pericytes [40]. The participation of pericytes during wound healing has already been described, and currently they are supposed to work as reserve cells, since their potential to differentiate into osteoblasts, chondrocytes, fibroblasts, leionyocytes and lipoblasts has been previously studied [41]. Despite there is a close resemblance in the phenotype of myofibroblasts and pericytes, their true relationship and association with the healing process is in need of further investigations.

In conclusion, we demonstrated that collagen-based films containing liposome-loaded usnic acid are quite useful in improving burn healing. Moreover, it is also suggested that this improvement is probably related to the modulation of some of the biological events involved in this process, such

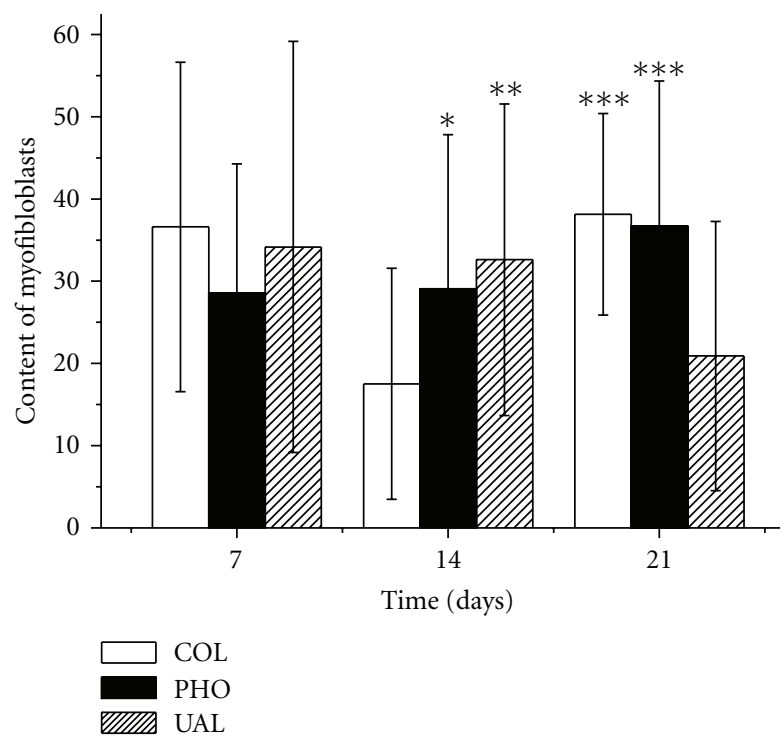

FIGURE 6: Quantitative analysis of the myofibroblasts content in the studied groups seven, 14 and 21 days after the burn procedures (COL—collagen-based dressing films; $\mathrm{PHO}$ - phospholipidscontaining collagen-based dressing films; UAL-liposome-loaded usnic acid-containing dressing films). ${ }^{*}$ Different from COL $P=$ .005 ; ${ }^{* *}$ Different from COL $P=.000 ;{ }^{* * *}$ Different from UAL $P=.000 ; * * *$ Different from UAL $P=.002$.

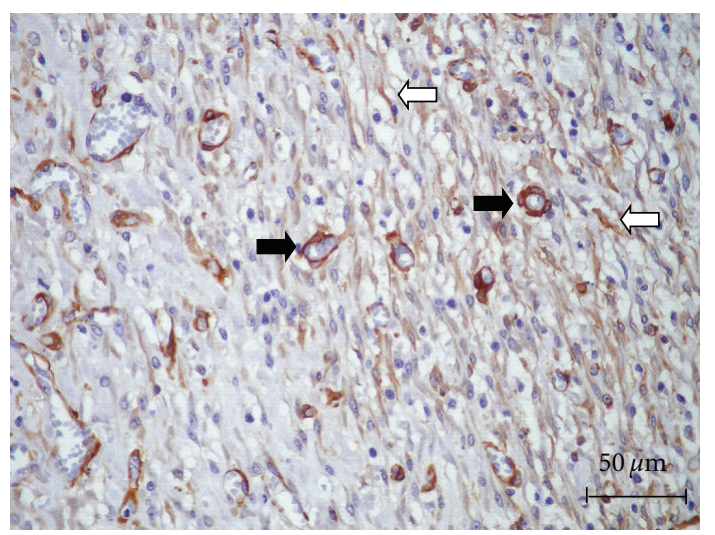

FIGURE 7: Pattern of immunohistochemical expression of $\alpha$ SMA (UAL, 14 days). Positive cells scattered in the connective tissue, parallel arranged in relation to the collagen fibers (white arrows), were regarded as myofibroblasts. Positive cells disposed, surrounding the newly formed blood vessels (black arrows) were considered pericytes (Immunohistochemistry, LSAB).

as the inflammatory response, epithelization, and collagen formation.

\section{Acknowledgments}

The authors would like to thank the National Council of Technological and Scientific Development (Conselho Nacional de Desenvolvimento Científico and Tecnológico/CNPq/ Brazil) and the Research Supporting Foundation of State of 
Brazil Sergipe (Fundação de Amparo à Pesquisa do Estado de Sergipe/FAPITEC-SE) for the financial support.

\section{References}

[1] C. Alemdaroğlu, Z. Değim, N. Çelebi, F. Zor, S. Öztürk, and D. Erdoǧan, "An investigation on burn wound healing in rats with chitosan gel formulation containing epidermal growth factor," Burns, vol. 32, no. 3, pp. 319-327, 2006.

[2] S. V. Hosseini, N. Tanideh, J. Kohanteb, Z. Ghodrati, D. Mehrabani, and H. Yarmohammadi, "Comparison between Alpha and Silver Sulfadiazine ointments in treatment of Pseudomonas infections in 3rd degree burns," International Journal of Surgery, vol. 5, no. 1, pp. 23-26, 2007.

[3] S. Aoyagi, H. Onishi, and Y. Machida, "Novel chitosan wound dressing loaded with minocycline for the treatment of severe burn wounds," International Journal of Pharmaceutics, vol. 330, no. 1-2, pp. 138-145, 2007.

[4] R. C. G. Girardi, Comportamento de matrizes de colágeno utilizadas no tratamento de feridas planas induzidas em pele de rato, dissertação, Universidade de São Carlos, São Paulo, Brazil, 2005.

[5] S. Mali, M. V. E. Grossmann, M. A. García, M. N. Martino, and N. E. Zaritzky, "Effects of controlled storage on thermal, mechanical and barrier properties of plasticized films from different starch sources," Journal of Food Engineering, vol. 75, no. 4, pp. 453-460, 2006.

[6] D. Gopinath, M. R. Ahmed, K. Gomathi, K. Chitra, P. K. Sehgal, and R. Jayakumar, "Dermal wound healing processes with curcumin incorporated collagen films," Biomaterials, vol. 25, no. 10, pp. 1911-1917, 2004.

[7] C. Helary, L. Ovtracht, B. Coulomb, G. Godeau, and M. M. Giraud-Guille, "Dense fibrillar collagen matrices: a model to study myofibroblast behaviour during wound healing," Biomaterials, vol. 27, no. 25, pp. 4443-4452, 2006.

[8] W. Friess, "Collagen-biomaterial for drug delivery," European Journal of Pharmaceutics and Biopharmaceutics, vol. 45, no. 2, pp. 113-136, 1998.

[9] J. B. Stark, E. D. Walter, and H. S. Owens, "Method of isolation of usnic acid from Ramalina reticulata," Journal of the American Chemical Society, vol. 72, no. 4, pp. 1819-1820, 1950.

[10] S. Huneck and K. Schreiber, "Wachstumsregulatorische eigenschaften von flechten-und moos-inhaltsstoffen," Phytochemistry, vol. 11, no. 8, pp. 2429-2434, 1972.

[11] M. A. Bazin, A. C. L. Lamer, J. G. Delcros et al., "Synthesis and cytotoxic activities of usnic acid derivatives," Bioorganic and Medicinal Chemistry, vol. 16, no. 14, pp. 6860-6866, 2008.

[12] R. R. Bomfim, A. A. S. Araújo, S. Cuadros-Orellana et al., "Larvicidal Activity of Cladonia substellata Extract and Usnic Acid against Aedes aegypti and Artemia salina," Latin American Journal of Pharmacy, vol. 28, no. 4, pp. 580-584, 2009.

[13] M. Cardarelli, G. Serino, L. Campanella et al., "Antimitotic effects of usnic acid on different biological systems," Cellular and Molecular Life Sciences, vol. 53, no. 8, pp. 667-672, 1997.

[14] M. Takai, Y. Uehara, and J. A. Beisler, "Usnic acid derivatives as potential antineoplastic agents," Journal of Medicinal Chemistry, vol. 22, no. 11, pp. 1380-1384, 1979.

[15] N. P. da Silva Santos, S. C. Nascimento, M. S. O. Wanderley et al., "Nanoencapsulation of usnic acid: an attempt to improve antitumour activity and reduce hepatotoxicity," European
Journal of Pharmaceutics and Biopharmaceutics, vol. 64, no. 2, pp. 154-160, 2006.

[16] K. Ingólfsdóttir, G. A. C. Chung, V. G. Skúlason, S. R. Gissurarson, and M. Vilhelmsdóttir, "Antimycobacterial activity of lichen metabolites in vitro," European Journal of Pharmaceutical Sciences, vol. 6, no. 2, pp. 141-144, 1998.

[17] Y. Yamamoto, Y. Miura, Y. Kinoshita et al., "Screening of tissue cultures and thalli of lichens and some of their active constituents for inhibition of tumor promoter-induced Epstein-Barr virus activation," Chemical and Pharmaceutical Bulletin, vol. 43, no. 8, pp. 1388-1390, 1995.

[18] M. C. B. Lira, M. S. Ferraz, D. G. V. C. da Silva et al., "Inclusion complex of usnic acid with $\beta$-cyclodextrin: characterization and nanoencapsulation into liposomes," Journal of Inclusion Phenomena and Macrocyclic Chemistry, vol. 64, no. 3-4, pp. 215-224, 2009.

[19] C. M. Batista, C. M. B. De Carvalho, and N. S. S. Magalhães, "Lipossomas e suas aplicações terapêuticas: Estado da arte," Revista Brasileira de Ciencias Farmaceuticas, vol. 43, no. 2, pp. 167-179, 2007.

[20] N. S. Santos-Magalhães and V. C. F. Mosqueira, "Nanotechnology applied to the treatment of malaria," Advanced Drug Delivery Reviews, vol. 62, no. 4-5, pp. 560-575, 2010.

[21] C. A. S. Andrade, N. S. Santos-Magalhães, and C. P. de Melo, "Thermodynamic characterization of the prevailing molecular interactions in mixed floating monolayers of phospholipids and usnic acid," Journal of Colloid and Interface Science, vol. 298, no. 1, pp. 145-153, 2006.

[22] C. Sinico, M. Manconi, M. Peppi, F. Lai, D. Valenti, and A. M. Fadda, "Liposomes as carriers for dermal delivery of tretinoin: in vitro evaluation of drug permeation and vesicleskin interaction," Journal of Controlled Release, vol. 103, no. 1, pp. 123-136, 2005.

[23] R. R. C. New, In Liposomes: A Practical Approach, IRL Press, Oxford, UK, 1992.

[24] J. C. Cardoso, Desenvolvimento de gel a partir de colágeno modificado para liberação prolongada de fármacos, dissertação, Universidade de São Paulo, Faculdade de Ciências Farmacêuticas, Ribeirão Preto, Brazil, 2005.

[25] S. M. Kupchan and H. L. Kopperman, "1-Usnic acid: tumor inhibitor isolated from lichens," Experientia, vol. 31, no. 6, pp. 625-626, 1975.

[26] P. S. Nunes, M. S. Bezerra, L. P. Costa et al., "Thermal characterization of usnic acid/collagen-based films," Journal of Thermal Analysis and Calorimetry, vol. 99, no. 3, pp. 10111014, 2010.

[27] M. A. G. Ribeiro, R. L. C. Albuquerque, L. M. P. Ramalho, A. L. B. Pinheiro, L. R. Bonjardim, and S. S. Da Cunha, "Immunohistochemical assessment of myofibroblasts and lymphoid cells during wound healing in rats subjected to laser photobiomodulation at $660 \mathrm{~nm}$," Photomedicine and Laser Surgery, vol. 27, no. 1, pp. 49-55, 2009.

[28] R. F. Diegelmann and M. C. Evans, "Wound healing: an overview of acute, fibrotic and delayed healing," Frontiers in Bioscience, vol. 9, pp. 283-289, 2004.

[29] S. Srivastava, S. D. Gorham, D. A. French, A. A. Shivas, and J. M. Courtney, "In vivo evaluation and comparison of collagen, acetylated collagen and collagen/glycosaminoglycan composite films and sponges as candidate biomaterials," Biomaterials, vol. 11, no. 3, pp. 155-161, 1990.

[30] C. S. Vijayakumar, S. Viswanathan, M. K. Reddy, S. Parvathavarthini, A. B. Kundu, and E. Sukumar, "Antiinflammatory activity of (+)-usnic acid," Fitoterapia, vol. 71, no. 5, pp. 564-566, 2000. 
[31] J. Jin, Y. Dong, and L. He, "The study on skin wound healing promoting action of sodium usnic acid," Zhong Yao Cai, vol. 28, no. 2, pp. 109-111, 2005.

[32] B. Burlando, E. Ranzato, A. Volante, G. Appendino, F. Pollastro, and L. Verotta, "Antiproliferative effects on tumour cells and promotion of keratinocyte wound healing by different lichen compounds," Planta Medica, vol. 75, no. 6, pp. 607-613, 2009.

[33] E. C. M. De Melo, M. Lemos, J. A. Ximenes Filho, L. U. Sennes, P. H. Nascimento Saldiva, and D. H. Tsuji, "Distribution of collagen in the lamina propria of the human vocal fold," Laryngoscope, vol. 113, no. 12, pp. 2187-2191, 2003.

[34] A. F. N. Ramos and J. L. De Miranda, "Propolis: a review of its anti-inflammatory and healing actions," Journal of Venomous Animals and Toxins Including Tropical Diseases, vol. 13, no. 4, pp. 697-710, 2007.

[35] C. D. G. Carneiro, L. U. Sennes, P. H. N. Saldiva, D. H. Tsuji, and J. A. Ximenes Filho, "Avaliação da deposição de colágeno após implante de fáscia lata e de gordura na prega vocal de coelho: Estudo histomorfométrico," Revista Brasileira de Otorrinolaringologia, vol. 71, no. 6, pp. 798-802, 2005.

[36] L. Rich and P. Whittaker, "Collagen and picrosirius red staining: a polarized light assessment of fibrillar hue and spatial distribution," Brazilian Journal of Morphological Sciences, vol. 22, pp. 97-104, 2005.

[37] V. C. Sandulache, A. Parekh, H. Li-Korotky, J. E. Dohar, and P. A. Hebda, "Prostaglandin E2 inhibition of keloid fibroblast migration, contraction, and transforming growth factor (TGF)- $\beta 1$-induced collagen synthesis," Wound Repair and Regeneration, vol. 15, no. 1, pp. 122-133, 2007.

[38] P. D. H. M. Verhaegen, P. P. M. Van Zuijlen, N. M. Pennings et al., "Differences in collagen architecture between keloid, hypertrophic scar, normotrophic scar, and normal skin: an objective histopathological analysis," Wound Repair and Regeneration, vol. 17, no. 5, pp. 649-656, 2009.

[39] H. E. Van Beurden, J. W. Von Den Hoff, R. Torensma, J. C. Maltha, and A. M. Kuijpers-Jagtman, "Myofibroblasts in palatal wound healing: prospects for the reduction of wound contraction after cleft palate repair," Journal of Dental Research, vol. 84, no. 10, pp. 871-880, 2005.

[40] M. C. M. C. Pereira, C. B. D. Pinho, A. R. P. Medrado, Z. D. A. Andrade, and S. R. D. A. Reis, "Influence of $670 \mathrm{~nm}$ low-level laser therapy on mast cells and vascular response of cutaneous injuries," Journal of Photochemistry and Photobiology B, vol. 98, no. 3, pp. 188-192, 2010.

[41] C. Farrington-Rock, N. J. Crofts, M. J. Doherty, B. A. Ashton, C. Griffin-Jones, and A. E. Canfield, "Chondrogenic and adipogenic potential of microvascular pericytes," Circulation, vol. 110, no. 15, pp. 2226-2232, 2004. 


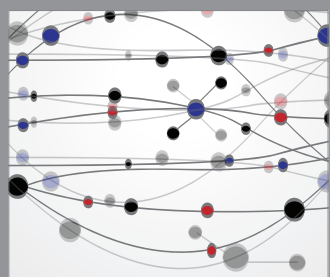

The Scientific World Journal
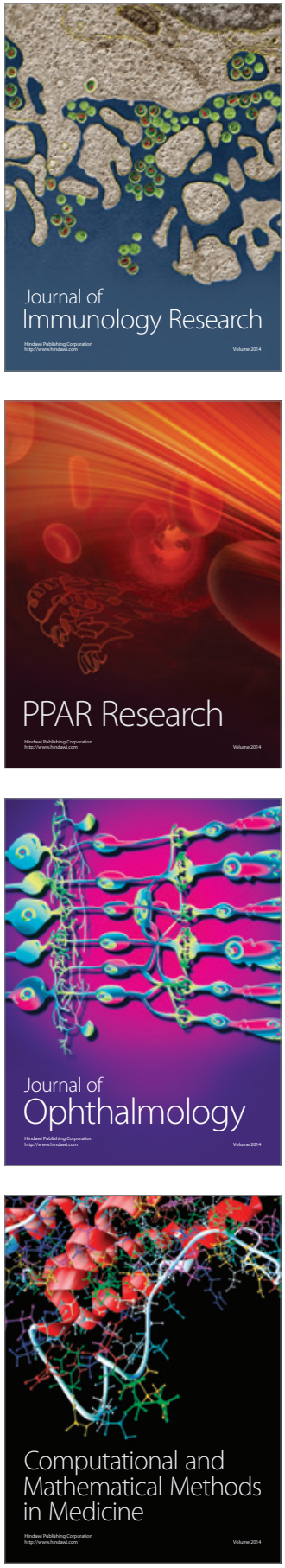

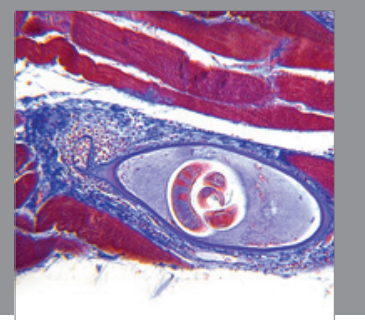

Gastroenterology

Research and Practice
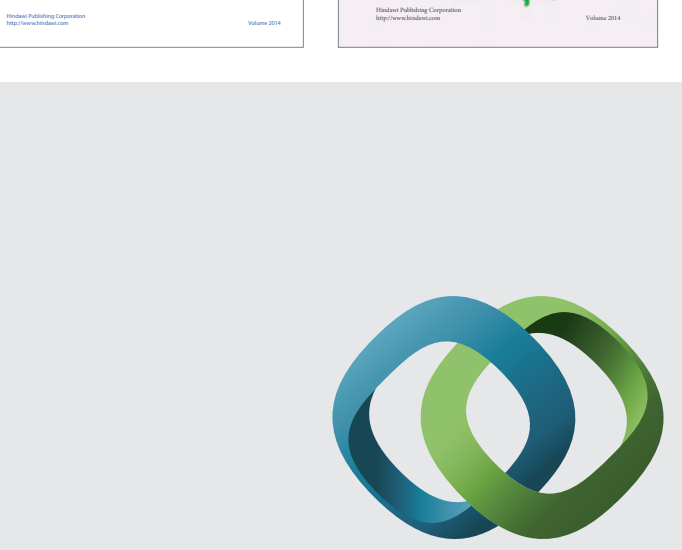

\section{Hindawi}

Submit your manuscripts at

http://www.hindawi.com
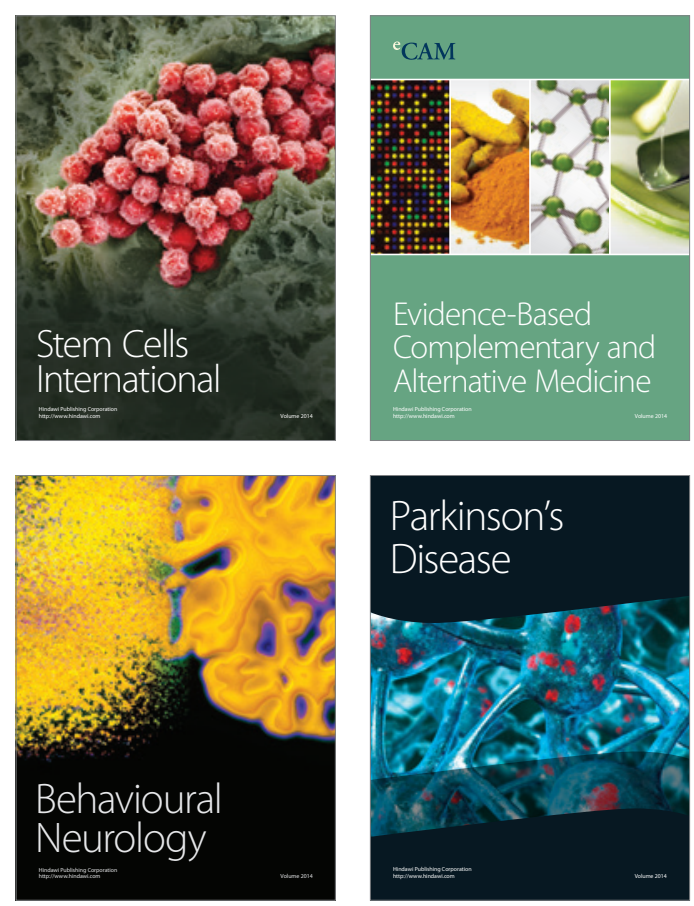

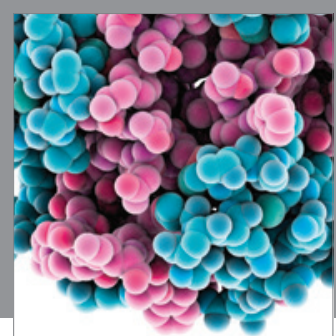

Journal of
Diabetes Research

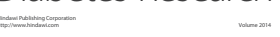

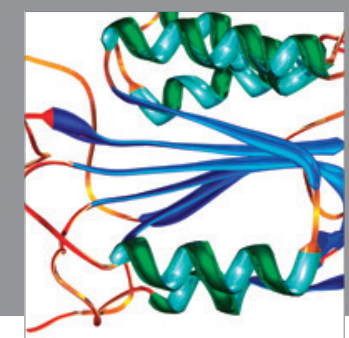

Disease Markers
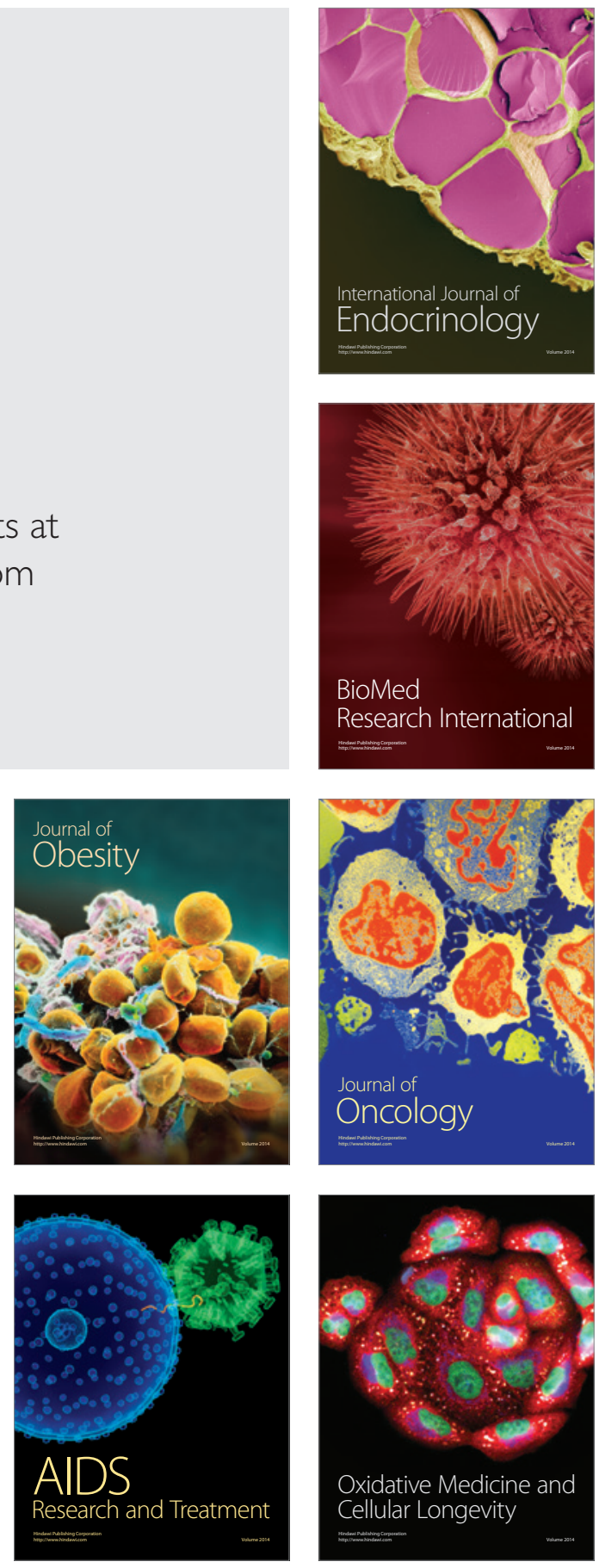